\title{
ORYGINALNE PODEJŚCIE DO BADANIA BUEGARSKIEGO OBRZĘDU WESELNEGO
}

\author{
PETAR SOTIROV \\ Maria Curie-Sklodowska University in Lublin
}

\begin{abstract}
AN ORIGINAL APPROACH TO RESEARCH ON BULGARIAN WEDDING RITE. A review of: Mleczko, Joanna. The Traditional Bulgarian Wedding Rite. An Ethnolinguistic Study. Katowice: University of Silesia Press, 2018, 394 pp. ISBN 978-83-226-3197-3 [in Polish: Tradycyjny butgarski obrzęd weselny. Studium etnolingwistyczne. Katowice: Wydawnictwo Uniwersytetu Śląskiego, 2018].

Keywords: wedding rite, Bulgarian folklore, ethnolinguistic study, Joanna Mleczko
\end{abstract}

W ostatnim czasie na rynku wydawniczym pojawiła się książka polskiej bułgarystki Joanny Mleczko pt. Tradycyjny bułgarski obrzęd weselny. Studium etnolingwistyczne. Katowice: Wydawnictwo Uniwersytetu Śląskiego, 2018, ss. 394. Monografia jest pokłosiem wieloletnich badań autorki, która jest dobrze znana w środowisku naukowym z poprzednich publikacji na ten sam temat. Książkę wyróżnia bardzo bogata treść - składa się ona ze wstępu, trzech głównych części, zakończenia, bibliografii, wykazu źródeł, rozwiązania skrótów, słownika terminów i nazw realiów, indeksu pieśni, indeksu terminów, indeksu osobowego, streszczenia w języku bułgarskim i francuskim. Po zapoznaniu się z poszczególnymi komponentami można się upewnić, że każdy z nich został opracowany niezwykle precyzyjnie, a cały układ w pełni odpowiada specyfice rozpracowywanego problemu badawczego.

Należy przyznać, że wybierając tradycyjny bułgarski obrzęd weselny jako obiekt dociekań naukowych, Joanna Mleczko stanęła przed bardzo trudnym zadaniem. Wynika to z faktu, że obiekt ten, w różnych aspektach, był już omawiany przez wielu badaczy. Autorka musiała więc znaleźć nowy, specyficzny punkt widzenia i zaproponować własne rozwiązanie metodologiczne, żeby przeprowadzone badania były uzasadnione. Można powiedzieć, że podtytuł pracy - Studium etnolingwistyczne - stanowi już pewną przesłankę do rozumienia istoty autorskiego pomysłu, a bardziej szczegółowo pomysł ten został wyłożony w części wstępnej, natomiast jego realizację uwidaczniają wszystkie części analityczne.

Wstępna cześć książki (s. 7-29) ma charakter teoretyczno-opisowy. Zawiera ona ważkie dla rozumienia całej pracy informacje, w szczególności znalazły się tutaj: wyjaśnienia 
terminologiczne, prezentacja stanu dotychczasowych badań, informacje o układzie pracy, charakterystykę źródeł oraz zasady ich przywoływania i cytowania, cele badawcze i założenia metodologiczne. Ustalenia terminologiczne, które zostały wyłożone na początku części wstępnej, okazały się niezbędne, ponieważ autorka udowodniła, że zarówno na poziomie empirycznym, jak i w przestrzeni naukowej brakuje jednolitego zrozumienia podstawowych terminów, na przykład takich jak obyczaj i obrzęd, które w pracy zajmują centralne miejsce. Jako punkt wyjściowy do traktowania terminu obrzęd przyjęto definicję założyciela i wybitnego przedstawiciela moskiewskiej szkoły etnolingwistycznej Nikity Tołstoja, który obrzęd określił jako tekst kultury z dwoma poziomami (werbalnym i rytualnym), każdy ze swoimi kodami (np. akcjonalnym, personalnym, przedmiotowym, temporalno-przestrzennym, muzycznym) (Tolstoy 1995a; 1995b).

W tejże części bardzo szczegółowo zaprezentowano również dotychczasowy stan badań nad bułgarskim tradycyjnym obrzędem weselnym. Z zamieszczonej informacji wynika, że autorka zapoznała się dogłębnie zarówno z bogatym zasobem archiwalnym Bułgarskiej Akademii Nauk, jak i z licznymi publikacjami na temat badanego obiektu. Tutaj czytelnik znajdzie chronologicznie uporządkowaną prezentację zarówno opracowań etnograficznych, które odtwarzają przebieg obrzędu weselnego, jak i folklorystycznych, które przedstawiają towarzyszącą mu oprawę artystyczną (słowną i muzyczną). Całkowicie zasadnie bardziej szczegółowo omówiono publikacje, w których obrzęd weselny poddany jest krytycznej analizie, w związku z tym w centrum uwagi znalazły się dzieła najwybitniejszych badaczy bułgarskich, np. Michaiła Arnaudowa (Arnaudov 1931; 1971), Christa Wakarełskiego (Vakarelski 1939), Nikołaja Kaufmana ( Kaufman 1976), Radost Iwanowej (Ivanova 1984) i in. Nie zostały pominięte również dokonania uczonych, którzy badali bułgarski obrzęd weselny na tle ogólnosłowiańskim, np. Aleksandra W. Gury (Gura 2012), Jana Komorovskiego (Komorovsky 1976) i in. Dobre wrażenie sprawia fakt, że podawanej informacji ciągle towarzyszy komentarz autorski, który nie tylko określa wartość komentowanej publikacji, ale ale uzasadnia również powstanie zaproponowanej książki z przyjętym w niej podejściem etnolingwistycznym.

Za szczególnie istotny dla rozumienia zamysłu autorskiego można uznać rozdział pt. Układ pracy (s. 20-26) części wstępnej, w którym zawarte są nie tylko informacje na temat treści poszczególnych części i ich rozdziałów, ale również ujawnione są cele badawcze i przyjęty sposób analizy materiału. Dowiadujemy się bowiem, że praca stanowi próbę nie tyle odtworzenia przebiegu tradycyjnego bułgarskiego obrzędu weselnego [...], ile odkrycia symbolicznych znaczeń, jakie mają elementy poszczególnych kodów obrzędowych (s. 21). Dalej wyjaśniono, że celem autorki jest również zaprezentowanie inwariantu bułgarskiego wesela tradycyjnego z uwzględnieniem elementów obligatoryjnych i fakultatywnych (s. 22). 
Jako element modelu badawczego i jako dowód etnolingwistycznego charakteru podjętych badań służy zapewnienie, że dane etnograficzne traktowane są na równi z danymi językowymi (s. 21). Więc, można przyjąć, że zapewnienie to implikuje informację o tym, czym się różni obecne badanie od dotychczasowych. Opisując zaś operacjonalny model analizy autorka oznajmia, że kod akcjonalny jest brany jako punkt wyjściowy, a poszczególne działania rytualne przywołane są w pracy na podstawie głównie 2 kryteriów - kryterium semantycznego, czyli związku działania z podstawowymi semantycznymi dominantami wesela, oraz kryterium pełnionej przez nie funkcji (np. przyciągająca, odpychająca, profilaktyczna, apotropeiczna, katartyczna i in.) (s. 21-22). Wstępną część rozprawy zamykają charakterystyka wykorzystanych źródeł oraz opis zasad ich przywoływania i cytowania, które niewątpliwie pomagają w recepcji całego tekstu.

Najbardziej rozbudowaną część monografii stanowi jej część analityczna, która obejmuje 300 stron (s. 33-326). Jest to logiczne mając na uwadze, że tutaj została zaprezentowana analiza wszystkich, bardzo licznych, komponentów etapów i odrębnych epizodów, z których składa się rytuał weselny jako tekst kultury i jako rite de passage. Chronologia analizy naśladuje utrwalony w badaniach nad rytuałem przejścia trójpodział, który uwzględnia: obrzędowość przedweselną, wesele właściwe i obrzędowość poweselną. W ramach każdego etapu wyodrębniono oddzielne komponenty w postaci działań, przedmiotów, subiektów wykonujących różne role, formuł słownych i in., które są składnikami omawianego etapu wesela. W części analitycznej pracy najbardziej rozbudowany jest tekst poświęcony weselu właściwemu, który składa się z 12 rozdziałów (s. 127-288). Jest to oczekiwane ze względu na fakt, że ten etap obrzędu weselnego jest najbardziej bogaty pod względem uczestniczących subiektów, czynności, rekwizytów, rytuałów, oprawy artystycznej itd. Na przykład występuje tutaj przygotowanie chlebów i innych rekwizytów, golenie pana młodego, zaplatanie włosów panny młodej, orszak weselny, ceremonia ślubna, uczta weselna i towarzyszące jej zwyczaje i rytuały. Krótsza jest natomiast część poświęcona obrzędowości przedweselnej (s. 33-126), która obejmuje 4 rozdziały (Zaloty, Swaty, Zaręczyny, Zapraszanie na wesele), oraz część uwzględniająca obrzędowość poweselną (s. 289-326, która również składa się z 4 rozdziałów (Pierwsze czynności, Prowadzenie młodej mężatki do wody, Odwiedziny, Pierwszy rok po weselu).

Wymieniona kolejność analizy nie jest cechą oryginalną rozprawy, gdyż w ten sam sposób rozpatrywano bułgarskie tradycyjne wesele przez innych badaczy, ale novum w przypadku pracy dr Joanny Mleczko stanowi model analizy, który został określony we wstępie tekstu rozprawy, a tutaj zastosowano go konsekwentnie wobec wszystkich analizowanych komponentów obrzędu weselnego. Przytaczając jednocześnie dane etnograficzne i językowe, autorka podczas analizy każdego z tych komponentów zaprezentowała: treść 
zjawiska, jego nazwę (lub nazwy), semantykę i etymologię nazwy, znaczenie symboliczne oraz związaną ze zjawiskiem dokumentację językową w postaci tekstów folkloru (pieśni, przysłowia, zagadki i in.). Analizie towarzyszą liczne odwołania do publikacji na temat odpowiedniego aspektu omawianego zjawiska, które nie tylko świadczą o dobrze opanowanej wiedzy na temat opracowywanej problematyki, ale czynią z tekstu solidne kompendium informacji na temat bułgarskiego obrzędu weselnego. $\mathrm{W}$ wielu miejscach istota omawianego zjawiska została wyjaśniona w dużej mierze za pomocą etymologii i semantyki odpowiedniego terminu (lub terminów), przy tym autorka bazowała na ustaleniach innych badaczy, np. Eleny Uzeniowej (Uzeneva 2010), lub na dobrze znanych opracowaniach leksykograficznych, np. słownika języka bułgarskiego Najdena Gerowa (1895-1904) i słownika etymologicznego Wiesława Borysia (2008). Pokazano, że w przypadku niektórych rytuałów, subiektów, rekwizytów i innych komponentów bogactwo terminologii jest imponujące (np. w związku ze swataniem młodych, zaręczynami i in.), co potwierdza szczególną wagę tych komponentów w obrzędzie weselnym. Zauważalne jest także to, że w trakcie analizy dokonano prawidłowej hierarchii podawanych informacji, pozostawiając ważniejsze z nich w tekście głównym i zamieszczając dodatkowe w przypisach. Niektóre z przypisów są szczególnie pożyteczne dla polskiego czytelnika, ponieważ wprowadzają do realiów bułgarskich i bałkańskich.

Sposób przeprowadzenia analizy można zilustrować choćby przykładem analizy epizodu swatania młodych. Jego poszczególne komponenty składające się z czynności (fizycznych i mentalnych), przedmiotów, formuł słownych i in. omówione są w kontekście konkretnych realiów i psychologii społecznej. Każde autorskie spojrzenie potwierdzone jest wyznacznikiem językowym w postaci tekstu folkloru lub faktu o charakterze etymologiczno-semantycznym. Na przykład fakt, że inicjatywa przy swataniu przynależy do strony męskiej potwierdzono przysłowiem: Dziewczyna wychodzi za mąż, kiedy ją zechca, a chłopak się żeni, kiedy mu się zachce (s. 67). Natomiast to, że w rodzinie chłopaka rolę decyzyjną odgrywają jego rodzice, zilustrowano dwiema pieśniami ludowymi - w jednej z nich wysyłanie swatów dokonuje się za zgodą chłopaka, w drugiej zaś - bez jego zgody, ale w obu przypadkach z inicjatywy rodziców (s. 68). Autorka pokazała, że sytuacja ta społecznie uzasadniona jest tzw. 'prawem ojca' oraz dominującą rolą starszego pokolenia, co poświadczono przysłowiem: Starszy wydaje polecenia, a młodszy słucha (s. 67). W ramach terminologii przytoczono i omówiono (w tym ich etymologię i semantykę) wyrazy takie, jak swat, sgleda, godeż i in. Oddzielny fragment analizy poświęcono czynnikom, od których zależy wybór dziewczyny i ewentualnej akceptacji propozycji swatania. Poprzez przytoczenie odpowiednich tekstów folkloru autorce udało się pokazać nie tylko rolę każdego z tych czynników, ale również ich odbiór psychologiczno-społeczny. 
Po przeczytaniu całej części analitycznej można stwierdzić, że jest ona dowodem, że materiał folklorystyczny i inne dane językowe (np. semantyka, synonimia, etymologia), zgodnie z zapowiedzią w części wstępnej, wykorzystane zostały nie jako reprezentacja elementów, które towarzyszą obrzędowi weselnemu, ale przede wszystkim jako źródło ujawniające konceptualizację analizowanego zjawiska. W wyniku takiej analizy pokazano nie tylko treść prezentowanego zjawiska (działania, subiektu, rekwizytu i in.), ale również sposób jego konceptualizacji wraz z jego znaczeniem symbolicznym i wagą aksjologiczną.

Zakończenie pracy (s. 327-330) ma charakter podsumowujący. Jeszcze raz przypomniano tutaj podstawowe obrzędy i zwyczaje, które budują treść obrzędowości przedweselnej, weselnej i poweselnej. Ważniejszą część zakończenia stanowią jednak wnioski na temat ich sensów symbolicznych, do odkrycia których autorka dążyła podejmując swoje badania za pomocą metodologii etnolingwistycznej, czyli opartej jednocześnie na danych etnograficznych i językowych. Autorka uznała za zasadne podkreślić szczególną rolę danych językowych, które stały się środkiem i narzędziem interpretacji sensów symbolicznych i funkcji, które konkretne czynności pełnią w planie semantycznym obrzędu (s. 329). Pokazując znaczenia symboliczne i funkcje przeanalizowanych czynności w ramach całego obrzędu weselnego zwrócono uwagę na kilka typów czynności o różnym charakterze, wśród nich: czynności wróżebne, przyciągające lub odpychające (podczas zalotów), czynności o charakterze profilaktycznym, apotropeicznym lub katarktycznym (w ramach opozycji swojego-obcego świata), czynności łączące i podporządkowujące (w związku ze zmianą statusu społecznego i włączeniem do nowej grupy społecznej) oraz czynności o sensie prokreacyjnym (w związku z ideą przedłużenia rodu). Z pełnym przekonaniem można stwierdzić, że sformułowane wnioski są bardzo logiczne, bowiem wynikają one z dokonanej i zaprezentowanej w poprzednich częściach analizy.

Strona formalna monografii również zasługuje na uznanie. Zastosowany język i styl posiadają wszystkie cechy tekstu naukowego, który jednocześnie stanowi wciągające opowiadanie o jednym z najważniejszych wydarzeń z życia Bułgara. Bibliografia przedmiotowa jest wyjątkowo bogata. W opracowaniu uwzględnione zostały wszystkie mające związek z tematem pozycje, zarówno autorów bułgarskich i polskich, jak i przedstawicieli międzynarodowej slawistyki. Wykorzystane źródła (publikowane i niepublikowane) zostały bardzo dokładnie opisane. Dodatkowy walor pracy stanowią słownik wybranych terminów i nazw realiów, a także indeksy (pieśni, terminów i osobowy).

Reasumując należy stwierdzić, że zaproponowana w omawianej książce problematyka jest ciekawa i istotna, dotyczy ona ważkiego zjawiska społeczno-psychologicznego, jakim jest bułgarski tradycyjny obrzęd weselny. Joannie Mleczko udało się znaleźć własne miejsce wśród autorów licznych publikacji na ten sam temat przede wszystkim dzięki 
oryginalnemu podejściu do niego, w czym pomogła jej zastosowana metodologia etnolingwistyczna. Zaprezentowana w pracy analiza jest bardzo dogłębna, uwzględnia ona wszystkie kody obrzędu weselnego jako tekstu kultury, a opis poszczególnych komponentów na podstawie danych etnograficznych i językowych buduje kompleksowy i bardzo bogaty obraz bułgarskiego tradycyjnego obrzędu weselnego. W związku z tym z pełnym przekonaniem uważam, że zaproponowana przez Wydawnictwo Uniwersytetu Śląskiego książka autorstwa Joanny Mleczko jest godna polecenia zarówno specjalistom etnolingwistom, etnologom czy folklorystom, jak i szerszemu gronu miłośników fascynujących tekstów o języku i kulturze.

\section{REFERENCES}

Arnaudov 1931: Arnaudov, Mihail. "Bulgarian Wedding Ceremonies. Ethnological and Folklore Studies. Part 1: Review of the Folk Customs." Annual of Sofia University. Faculty of History and Philology, book 27 (1931): 1-148. [In Bulgarian: Арнаудов, Михаил. „Българските сватбени обреди. Етноложки и фолклорни студии. Ч. 1: Преглед на обичаите у народа.“ Годишник на Софийския университет. Историко-филологически факултет, кн. 27 (1931): 1-148.]

Arnaudov 1971: Arnaudov, Mihail. Studies on Bulgarian Rites and Legends. Vol. 1. Sofia: BAS, 1971. [In Bulgarian: Арнаудов, Михаил. Студии върху българските обреди и легенди. Т. 1. София: БАН, 1971.]

Gura 2012: Gura, Aleksandr. V. Marriage and Wedding in Slavic Folk Culture. Sematics and Symbolism. Moscow: Indrik Press, 2012. [In Russian: Гура, Александр. В. Брак и свадьба в славянской народной культуре. Семантика и символика. Москва: Индрик, 2012.]

Ivanova 1984: Ivanova, Radost. The Bulgarian Folk Wedding. Sofia: BAS, 1984. [In Bulgarian: Иванова, Радост. Българската фолклорна сватба. София: БАН, 1984.]

Kaufman 1976: Kaufman, Nikolay. The Bulgarian Wedding Song. Sofia: Music Press House, 1976. [In Bulgarian: Кауфман, Николай. Българската сватбена песен. София: Музика, 1976.]

Komorovsky 1976: Komorovsky, Jan. The Traditional Wedding of the Slavs. Bratislava: Komensky University Press, 1976. [In Slovak: Komorovský, Jan. Tradičná svadba u Slovanov. Bratislava: Univerzita Komenského, 1976.]

Tolstoy 1995a: Tolstoy, Nikita I. “The Secondary Function of the Ritual Symbol.” In Tolstoy, N. I. Language and Folk Culture. Essays on Slavic Mythology and Ethnolinguistics: 167-184. Moscow: Indrik, 1995. [In Russian: Толстой, Никита И. „Вторичная функция обрядового символа." В: Толстой, Н. И. Язык и народная культура. Очерки по славянской мифологии и этнолингвистике: 167-184. Москва: Индрик, 1995.]

Tolstoy 1995b: Tolstoy, Nikita I. "From the Grammar of Slavic Rites." In Tolstoy, N. I. Language and Folk Culture. Essays on Slavic Mythology and Ethnolinguistics: 63-77. Moscow: Indrik, 1995. [In Russian: Толстой, Никита И. „Из грамматики славянских обрядов.” В: Толстой, Н. И. Язык 
и народная культура. Очерки по славянской мифологии и этнолингвистике: 63-77. Москва: Индрик, 1995.]

Uzeneva 2010: Uzeneva, Elena S. The Bulgarian Wedding. Ethnolinguistic Research. Moscow: Indrik, 2010. [In Russian: Узенёва, Елена С. Болгарская свадьба. Этнолингвистическое исследование. Москва: Индрик, 2010.]

Vakarelski 1939: Vakarelski, Hristo. "The Wedding Song. Its Place and Service in the Wedding Ceremony." Reports of the National Ethnographic Museum in Sofia, no 13 (1939): 1-128.

[In Bulgarian: Вакарелски, Христо. „Сватбената песен. Мястото и службата ѝ в сватбения обред." Известия на Народния етнографски музей в София, кн. 13 (1939): 1-128.]

Vakarelski 2007: Vakarelski, Hristo. Ethnography of Bulgaria. Sofia: BAS, 2007. [In Bulgarian: Вакарелски, Христо. Етнография на България. София: БАН, 2007.] 